\title{
PERANCANGAN SISTEM PENJUALAN KREDIT RUMAH PADA PT. SURYA KREDIT PINTAR
}

\author{
Shania Yunita ${ }^{1}$, Dwi Yulistyanti ${ }^{2}$, Surajiyo $^{3}$ \\ 1,2,3Teknik Informatika, Fakultas Teknik dan Ilmu Komputer, Universitas Indraprasta PGRI \\ Jalan Raya Tengah No 80, Kelurahan Gedong, Pasar Rebo, Jakarta Timur \\ 1․ㅗaniayunita2@gmail.com, ${ }^{2}$ unindra.dwiyulist@gmail.com, ${ }^{3}$ drssurajiyo@gmail.com
}

\begin{abstract}
ABSTRAK
Pada umumnya masalah yang dihadapi oleh perusahaan yang belum terkomputerisasi dengan baik adalah belum memilikinya sistem komputer yang terintegerasi dan data olahan tersebut masih tersimpan dalam masing-masing komputer belum memiliki database server.Tujuan Penelitian adalah untuk menghasilkan Aplikasi Sistem Kredit Rumah yang bertujuan pada penerapan sistemnya adalah antara lain, dapat untuk mengidentifikasi persediaan rumah agar dapat memberikan data yang tepat dan akurat. Dan juga mengidentifikasi data pembeli agar dapat memberikan data yang akurat. Membangun aplikasi yang terdapat fitur untuk pendataan transaksi yang menghasilkan data laporan bulanan. Metode penelitian yang digunakan adalah metode research and development, yaitu suatu metode penelitian berdasarkan pada fakta dan menggunakan analisis perbandingan dengan tujuan mengadakan generasi empiris, menetapkan konsep, membuktikan teori, mengembangkan teori, mengumpulkan data dan analisa data dalam waktu yang bersamaan. Hasil penelitian ini menunjukkah bahwa salah satu cara yang dapat digunakan oleh perusahaan dalam mengelola pengkreditan rumah, metode ini dapat mengefisienkan biaya pemesanan dan biaya penjualan rumah sehingga laba perusahaan dapat dioptimalkan.
\end{abstract}

Kata kunci : Penjualan, Kredit Rumah, Java

\begin{abstract}
In general, the problem faced by companies that have not been computerized properly is that they do not have an integrated computer system and the processed data is still stored in each computer and does not have a database server. The research objective is to produce a Home Loan System Application which aims at the application of the system, among others, to be able to identify home inventories in order to provide precise and accurate data. And also identify buyer data in order to provide accurate data. Build an application that has features for data collection transactions that generate monthly report data. The research method used is the research and development method, which is a research method based on facts and using comparative analysis with the aim of conducting empirical generation, establishing concepts, proving theories, developing theories, collecting data and analyzing data at the same time. The results of this study indicate that one of the ways that companies can use in managing home loans, this method can streamline ordering costs and home sales costs so that company profits can be optimized.
\end{abstract}

Key Word : Selling. Kredit, Java

\section{PENDAHULUAN}

Perkembangan teknologi saat ini begitu cepat. Salah satunya adalah teknologi informasi. Keberadaan teknologi informasi memberikan manfaat bagi kita untuk dapat memperoleh data dan informasi dengan mudah dan cepat, namun keakuratan data juga harus diperhatikan. Dengan adanya teknologi informasi, kita tidak hanya dapat memperoleh data dan informasi dengan mudah dan cepat, namun keakuratan data juga harus diperhatikan. Kredit rumah atau kpr, Teknologi informasi dalam konteks penjualan adalah hal yang sangat dibutuhkan pada perusahaan yang melakukan proses penjualan. Keakuratan data dan informasi pada penjualan sangat penting karena akan dijadikan sebuah pelaporan informasi pembukuan.

Menurut(Davis, 2013)mendefinisikan sistem sebagai perangkat dari beberapa unsur- unsur yang terdiri dari manusia, alat, konsep dan prosedur yang dihimpun menjadi satu untuk maksud dan tujuan bersama.

Menurut (Zakiyudin, 2016) suatu sistem memiliki karakteristik atau sifat-sifat tertentu yang mencirikan sebagai suatu sistem.

Menurut (Abdurahman, 2014)"aplikasi adalah program siap pakai yang dapat digunakan untuk menjalankan perintah-perintah dengan 
tujuan untuk mendapatkan hasil yang lebih akurat sesuai dengan tujuan pembuatan aplikasi tersebut.

Menurut (Fahmi, 2011), Kata kredit berasal dari bahasa latin yaitu credere, yang diterjemahkan sebagai kepercayaan atau credo yang berarti saya percaya. Kredit atau kepercayaan (trust) adalah ibarat sekeping mata uang logam yang tidak dapat dipisahkan, karena tidak akan mungkin adanya pemberian pinjaman tanpa adanya bangunan kepercayaan disana dan kepercayaan itu adalah sesuatu yang mahal harganya".

Menurut(Satzinger,2015) perancangan sistem adalah sekumpulan aktivitas yang menggambarkan secara rinci bagaimana sistem akan berjalan.

Menurut (Sutarman, 2012), informasi adalah sekumpulan fakta (data) yang diorganisasikan dengan cara tertentu sehingga mereka mempunyai arti bagi si penerima.

Menurut (Mustakini, 2012), merupakan bahwa terdapat tiga jenis kualitas informasi, antara lain: Accurate, Timeliness, Relavance

Menurut (Sutarman, 2012), nilai dari informasi ditentukan oleh lima hal, yaitu: Untuk memperoleh pemahaman dan manfaat. Untuk mendapatkan pengalaman. Pembelajaran yang terakumulasi sehingga dapat diaplikasikan dalam pemecahan masalah atau proses bisnis tertentu.

Menurut (Rizky, 2013) perancangan adalah sebuah proses untuk mendefinisikan sesuatu yang akan dikerjakan dengan menggunakan teknik yang bervariasi serta didalamnya melibatkan deskripsi mengenai arsitektur serta detail komponen dan juga keterbatasan yang akan dialami dalam proses pengerjaannya

Menurut (Kristanto, 2016), menjelaskan "Data flow diagram adalah suatu model logika data atau proses yang dibuat untuk menggambarkan dari mana asal data kemana tujuan data yang keluar dari sistem, dimana data tersimpan, proses apa yang menghasilkan data tersebut dan interaksi antara data tersimpan
Menurut (Ladjamudin, 2018) Diagram Konteks adalah diagram yang terdiri dari suatu proses menggambarkan ruang lingkup suatu sistem

Hasil penelitian yang bisa dijadikan acuan atau pembanding dalam kajian penelitian masalah sebagai berikut :

Perancangan Sistem Kredit Rumah Pada Pt. Surya Kredit Pintar, Berdasarkan hasil peneletian dapat disimpulkan bahwa sistem informasi penjualan kredit rumah dari hasil penelitian ini dapat memberi kemudahan akses informasi dan proses penjualan kredit rumah.

\section{METODE PENELITIAN}

Penelitian ini menggunakan metode grounded research dan system development life cycle (SDLC). SDLC digunakan pada langkahlangkah pengembangan sistem informasi komputerisasi.

\section{HASIL DAN PEMBAHASAN}

Aturan sistem penjualan rumah kredit yang diusulkan pada PT. Surya Kredit Pintar adalah sebagai berikut:

1. Pegawai sebagai admin akan login dan melakukan penginputan

2. Pegawai menginput data pegawai.

3. Pegawai menginput data pembeli.

4. Pegawai menginput data Rumah

5. Pegawai menginput Transaksi

6. Pegawai membuat laporan

Berikut ini merupakan gambaran tentang sistem yang diusulkan pada sistem penjualan kedit rumah pada pt. surya kredit pintar:

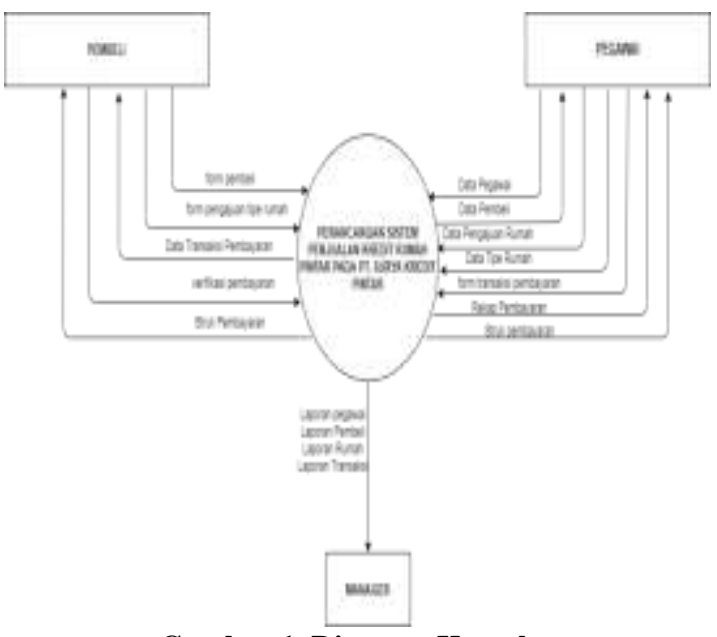

Gambar 1. Diagram Konteks 


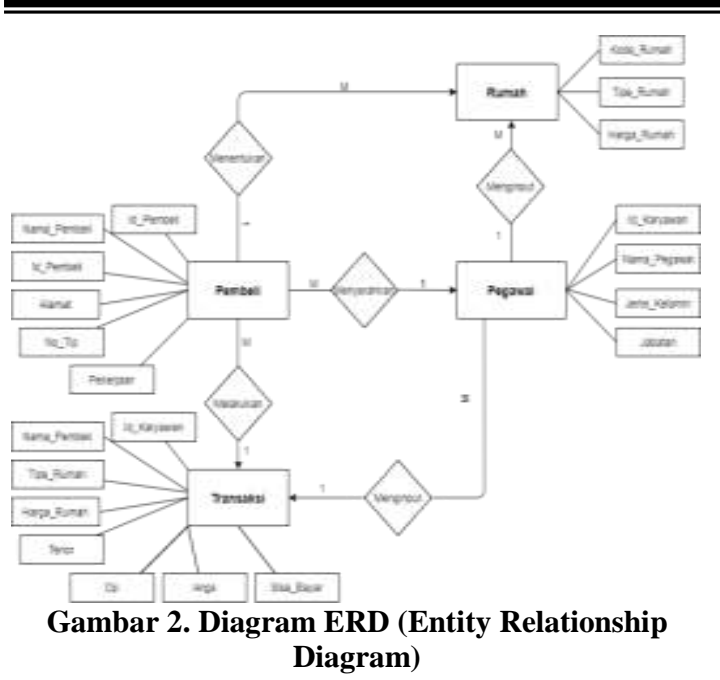

Selanjutnya penulis membuat aplikasi dengan menggunakan Java Netbeans berbasis desktop dan database mysql. Berikut ini adalah tampilan dari aplikasi sistem penjualan kredit rumah pada PT. Surya Kredit Pintar

\section{Tampilan Layar}

Form Login

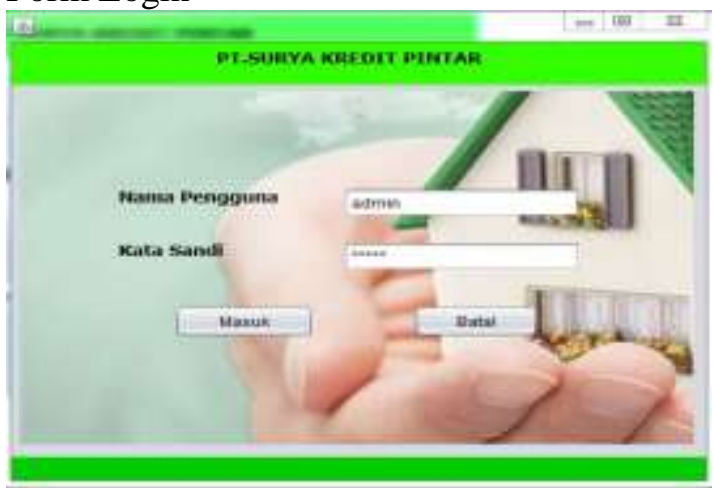

Gambar 3. Form login

pada proses semua pegawai dapat login termasuk owner dan manager dengan Nama pengguna dan kata sandi yang dibuat khusus untuk perusahaan mengakses aplikasi.

\section{Form Menu Utama}

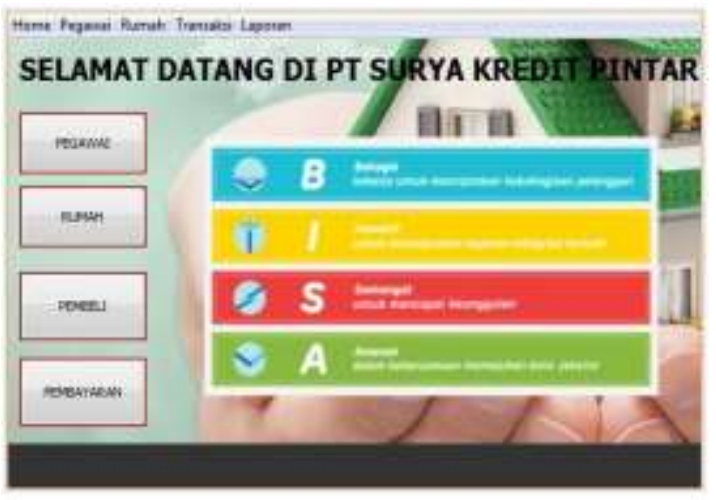

Gambar 4. Menu utama
Ini merupakan rancangan tampilan menu utama pada aplikasi kredit rumah untuk perusahaan.

Form masukan data pegawai

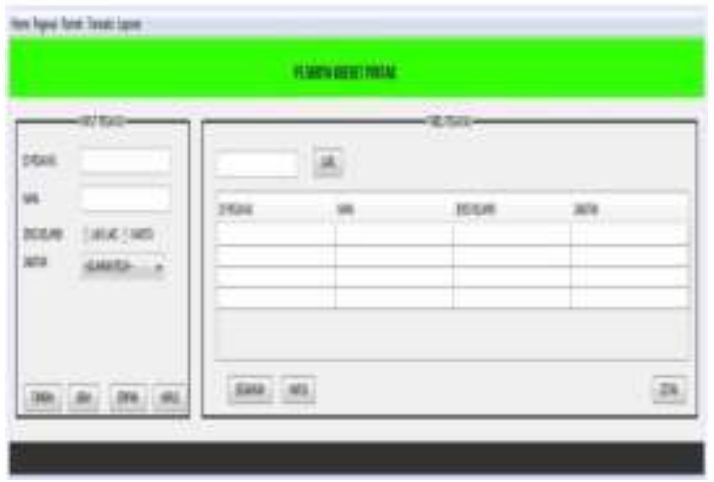

Gambar 5. Form pegawai

Pada form ini bertujuan untuk penginputan data pegawai yang berkerja dan melayani pembelian dan pembuatan laporan transaksi yang sedang diajukan oleh pembeli.

Form data pembeli

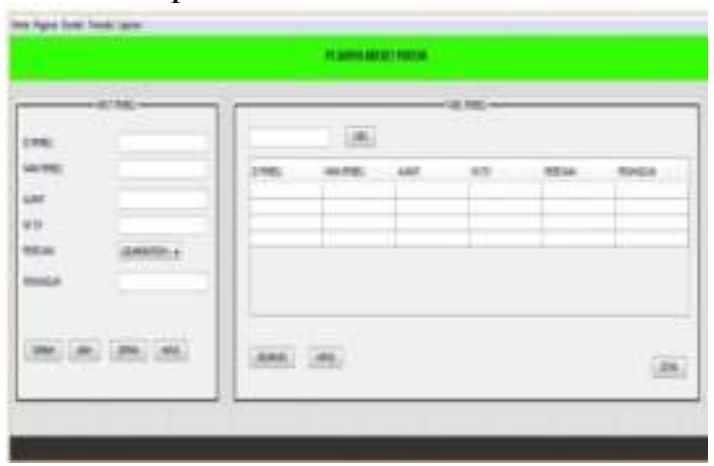

Gambar 6. Form pembeli

Pada proses ini pegawai meng input data pembeli yang telah diberikan oleh pembeli yang berisikan data diri yang akurat lalu disimpan.

Form data rumah

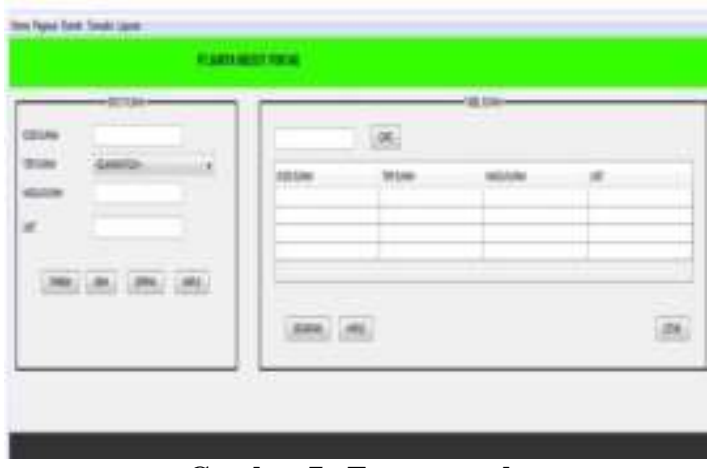

Gambar 7. Form rumah 
Pada menu ini pegawai menginput data tipe rumah sesuai dengan yang telah diajukan oleh pembeli seperti tipe tingkat lantai, luas rumah lalu akan disimpan.

Form data transaksi

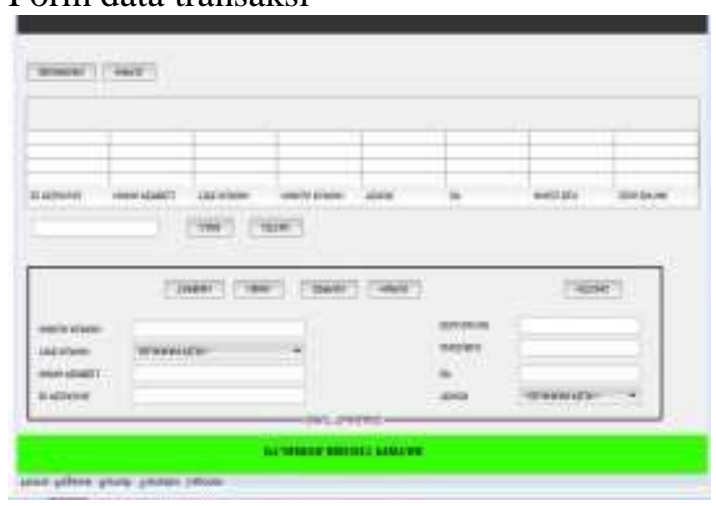

Gambar 8. Form transaksi

Pada proses ini adalah proses transaksi kredit rumah sesuai dengan tipe dan tenor yang telah ditentukan oleh pembeli, lalu setelah tenor di masukan pembeli harus memasukan total $\mathrm{dp}$ yang akan dibayarkan yang nantinya akan terhitung otomatis sisa bayar dan biaya angsuran perbulannya.

\section{Laporan Stock pegawai}

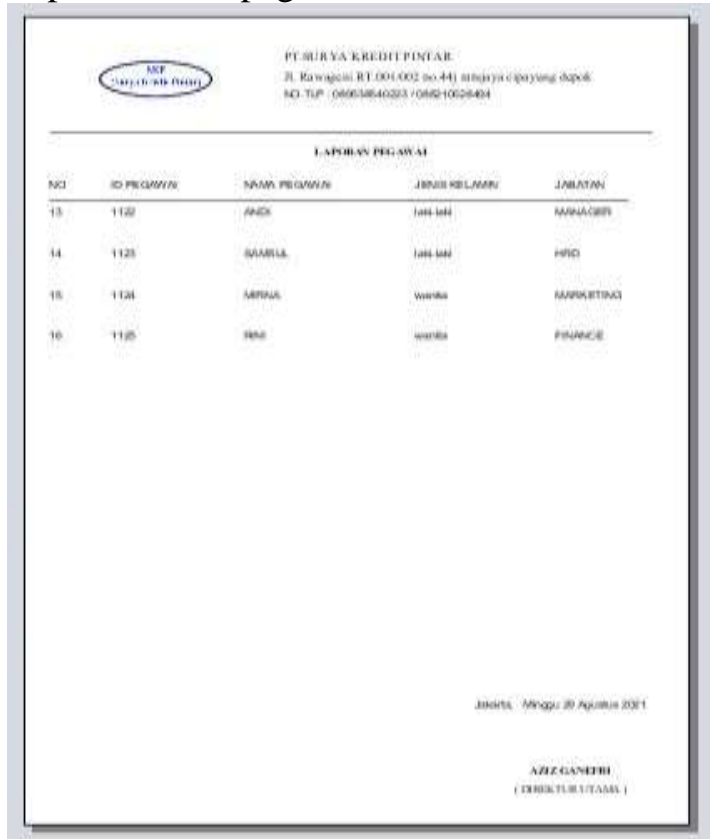

Gambar 9. Laporan pegawai

Ini adalah laporan pegawai setelah di cetak, laporan pegawai ini bisa juga diprint langsung
Laporan pembeli

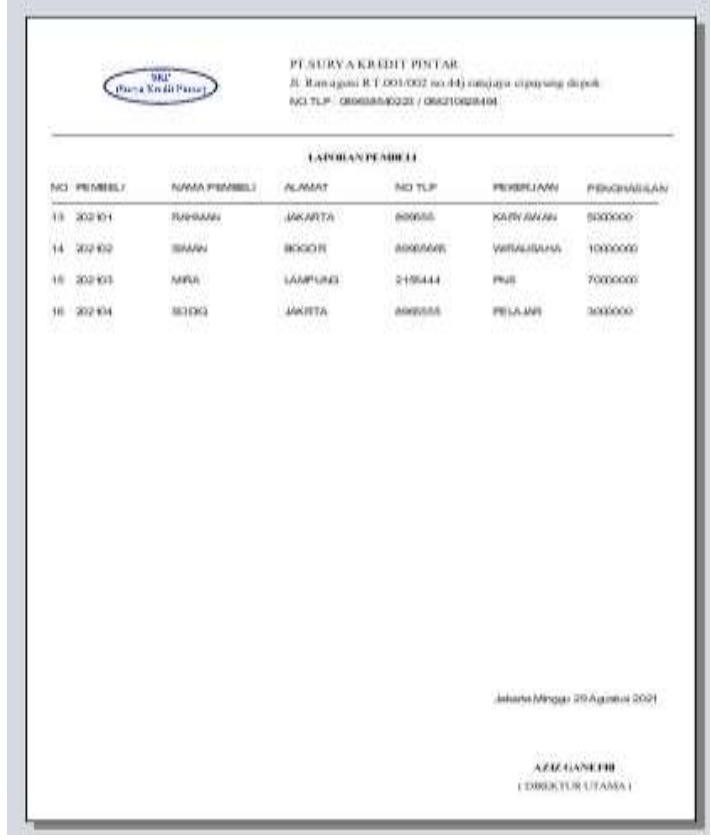

Gambar 10. Laporan pegawai

Ini adalah laporan pembeli setelah di cetak, laporan pembeli ini bisa juga diprint langsung.

Laporan rumah

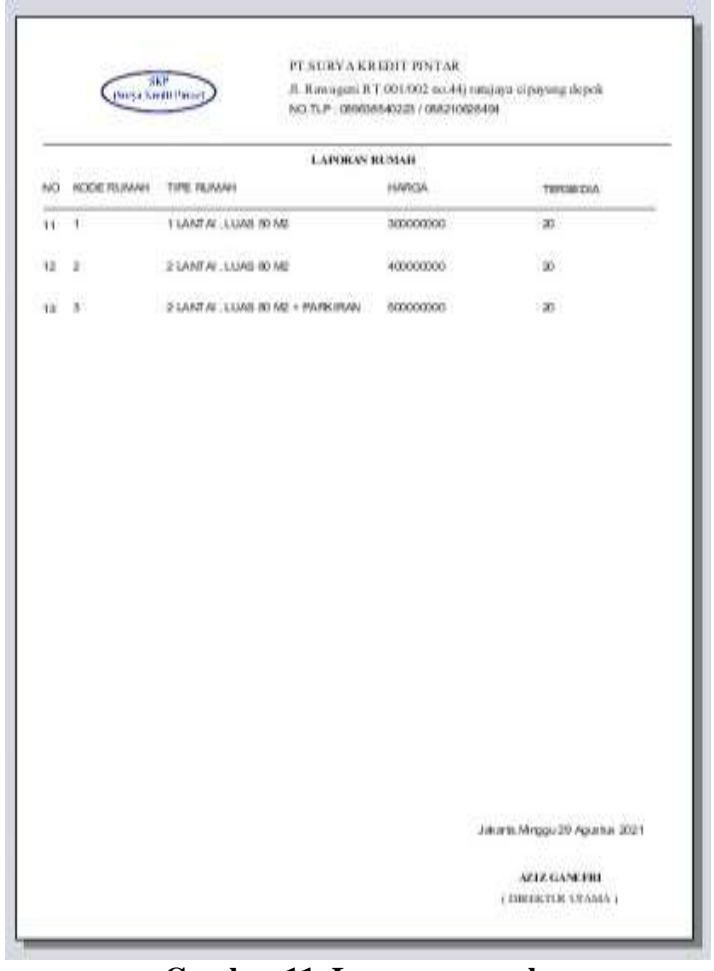

Gambar 11. Laporan rumah

Ini adalah laporan rumah setelah di cetak, laporan rumah ini bisa juga diprint langsung. 


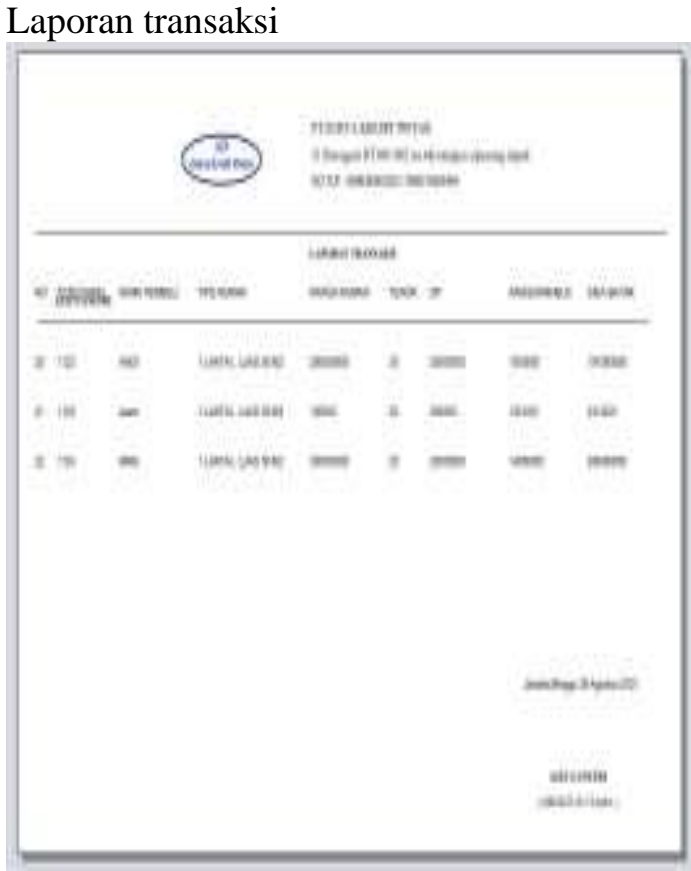

Gambar 12. Laporan transaksi

Ini adalah laporan transaksi setelah di cetak, laporan transaksi ini bisa juga diprint langsung.

\section{SIMPULAN DAN SARAN}

Berdasarkan penelitian yang telah dilakukan, didapatkan beberapa kesimpulan, antara lain:

1. Program yang dibuat dapat digunakan dengan baik dan mampu untuk menggantikan proses pencatatan manual dan transfer informasi yang sebelumnya hanya menggunakan Microsoft Excel.

2. Penggunaan program tidak dapat dilakukan oleh sembarang orang karena dilengkapi dengan sistem login.

3. Proses sistem informasi menjadi lebih akurat dan efisien serta penyajian laporan yang lebih terkordinasi sesuai kebutuhan yang diinginkan.

Penulis menyadari masih ada kekurangan dalam aplikasi ini. Oleh karena itu, agar aplikasi ini benar-benar menjadi aplikasi yang dapat mempermudah user dalam melakukan segala aktivitas yang berhubungan dengan pencatatan berbagai macam data informasi yang terjadi, antara lain: Dalam pengembangan selanjutnya diharapkan sistem ini tidak hanya mampu melakukan penyajian sistem informasi maintenance tetapi juga mampu melakukan pencatatana proses kredit rumah pada PT. Surya Kredit Pintar. Pada tahapan pengembangan selanjutnya, dapat ditambahkan beberapa prosedur enkripsi data yang berguna untuk meningkatkan sistem keamanan pada aplikasi.

1. Melakukan pelatihan pada admin di PT. Surya Kredit Pintar agar dapat memahami fungsi dan menggunakan aplikasi ini.

\section{DAFTAR PUSTAKA}

Abdurahman. (2014). DEFINISI APLIKASI. Angewandte Chemie International Edition, 6(11), 951-952., 8(2), 30-34. https://doi.org/10.26905/jtmi.v4i1.160 5

Davis, G. B. (2013). Analisa Perancangan Sistem. Definisi Sistem, 53(9), 35-39. https://doi.org/10.26905/jtmi.v4i1.160 5

Fahmi. (2011). Implementasi rasio keuangan untuk menilai kinerja keuangan. Jurnal WIGA, 3(2), 54-69.

Kristanto. (2016). Data Flow Diagram. https://doi.org/10.1007/978-3-54089556-5 4

Ladjamudin. (2018). Diagram Konteks. Jurnal Teknologi Dan Manajemen Informatika, 4(4), 75-81. https://doi.org/10.26905/jtmi.v4i1.160 5

Mustakini. (2012). Perancangan Sistem Informasi , Kualitas Informasi. https://doi.org/10.47927/jikb.v9i1.122

Rizky. (2013). Perancangan. Perancangan Sistem Informasi, 21(10), 25-29. https://doi.org/10.46984/sebatik.v22i2. 319

Satzinger. (2015). Pengertian perancangan sistem. Journal of Chemical Information and Modeling, 53(9), 1689-1699.

Sutarman. (2012). Definisi Informasi. Analisa Sistem Informasi Campus Service Iduhelp, 67(11), 57-63. https://doi.org/10.29207/resti.v4i4.221 8

Zakiyudin, M. (2016). Definisi Sistem Informasi Manajemen Menurut Zakiyudin sistem informasi. Angewandte Chemie International Edition, 6(11), 951-952., 48(9), 9-22. https://doi.org/10.26905/jtmi.v4i1.160 5 